\title{
Interleukin-10 Is an Independent Biomarker of Severe Traumatic Brain Injury Prognosis
}

\author{
Flávia Mahatma Schneider Soares ${ }^{a} \quad$ Nicole Menezes de Souza ${ }^{d} \quad$ Marcelo Liborio Schwarzbold ${ }^{a}$ \\ Alexandre Paim Diaz ${ }^{\mathrm{a}}$ Jean Costa Nunes ${ }^{\mathrm{a}}$ Alexandre Hohl ${ }^{\mathrm{a}}$ Priscilla Nunes Abreu da Silva ${ }^{\mathrm{a}}$ \\ Juliana Vieira ${ }^{a}$ Rafael Lisboa de Souza ${ }^{g}$ Melina Moré Bertotti ${ }^{f} \quad$ Rui Daniel Schoder Prediger ${ }^{e}$ \\ Marcelo Neves Linhares ${ }^{a, b}, f$ André Bafica ${ }^{d}$ Roger Walz ${ }^{a, c}$ \\ ${ }^{a}$ Centro de Neurociências Aplicadas, ${ }^{b}$ Departamento de Cirurgia e ${ }^{\mathrm{C}}$ Departamento de Clínica Médica, Hospital \\ Universitário, e d Laboratório de Imunofarmacologa e Doenças Infecciosas, e e Laboratório Experimental de \\ Doenças Neurodegenerativas, Departamento de Farmacologia, Universidade Federal de Santa Catarina, e \\ fServiço de Neurocirurgia e ${ }^{9}$ Serviço de Terapia Intensiva, Hospital Governador Celso Ramos, Florianópolis, Brasil
}

\section{Key Words}

Cytokines $\cdot$ IL-10 $\cdot$ TNF- $\alpha \cdot$ Traumatic brain injury •

Prognosis

\begin{abstract}
Background: Cytokines have been shown to be involved in traumatic brain injury (TBI). We investigated the independent association between serum levels of IL-10 and TNF- $\alpha$ and hospital mortality of patients with severe TBI. Methods: Serum IL-10 and TNF- $\alpha$ levels were determined after a median period (interquartile range (IQ) 25-75) of $10 \mathrm{~h}$ (IQ 5-18) after severe TBI in 93 consecutive patients and in randomly selected patients with mild $(n=18)$ and moderate $(n=16)$ TBI. In patients with severe TBI, additional blood samples were analyzed $30 \mathrm{~h}$ (IQ 22-37) and $68 \mathrm{~h}$ (IQ 55-78) after TBI. Age, gender, computed tomography findings, Glasgow Coma Scale score (GCS) and pupil reactions at admission, associated trauma and hospital mortality were collected. $\boldsymbol{R e}$ sults: Elevated serum levels of IL-10, but not TNF- $\alpha$, correlated significantly with GCS severity $\left(R^{2}\right.$ coefficient, $p<$ $0.0001)$ and were found to be associated with hospital mor-
\end{abstract}

\section{KARGER}

Fax +4161306 1234

E-Mail karger@karger.ch

www.karger.com
(C) 2012 S. Karger AG, Basel

$1021-7401 / 12 / 0196-0377 \$ 38.00 / 0$

Accessible online at:

www.karger.com/nim tality in patients with severe TBI. Elevated IL-10 remained associated with mortality $(p=0.01)$ in a subset of patients with isolated severe TBI $(n=74)$. Multiple logistic regression analysis showed that higher IL-10 levels $(>90 \mathrm{pg} / \mathrm{ml})$ at 10 or $30 \mathrm{~h}$ after TBI were 6 times (odds ratio (OR) 6.2, 95\% confidence interval $(\mathrm{Cl}) 1.2-25.1, \mathrm{p}=0.03)$ and 5 times $(\mathrm{OR} 5.4,95 \% \mathrm{Cl}$ $1.2-25.1, p=0.03)$, respectively, more frequently associated with hospital mortality than lower levels $(<50 \mathrm{pg} / \mathrm{ml})$, independently of age, GCS as well as pupil reactions at admission and associated trauma. Conclusions: Serum IL-10 levels may be a useful marker for severe TBI prognosis.

Copyright @ 2012 S. Karger AG, Basel

\section{Introduction}

Traumatic brain injury (TBI) is a leading cause of mortality $[1,2]$ and disability [3-5] among young adults and constitutes a major health and socioeconomic problem throughout the world. The extent of brain damage is determined by the severity of the primary mechanical injury and the consequences of secondary biomolecular in- 
jury cascades, which cause neuroinflammation and contribute to cerebral edema, enhanced intracranial pressure and delayed cellular damage [6-12]. TBI results in early inflammatory responses initiated by the release of diverse immune mediators as well as infiltration of polymorphonuclear leukocytes, which guide a sequence of events including expression of adhesion molecules, cellular infiltration, and additional secretion of inflammatory molecules and growth factors, resulting in either regeneration or cell death [9-14].

Cytokines are critical mediators of neuroinflammation after TBI $[7,8,11]$, regulating a wide variety of cellular functions through autocrine and paracrine signaling networks that may maintain uncontrolled immunopathology [8]. Increased synthesis and release of various pro- and anti-inflammatory cytokines into the CNS and blood is associated with severe TBI [6]. In animal models, for example, the induction of TNF- $\alpha$ and IL- $1 \beta$ peaks early within 3-8 h after injury, followed by more sustained elevations of IL- 6 and IL-10 $[13,15]$. TNF- $\alpha$ and IL-10 are produced in high concentrations by resident microglia and infiltrating monocytes/macrophages in the acute phase of injury [12]. Astrocyte reactivity is stimulated by inflammatory cytokines, contributing to increased neuroinflammation and the development of secondary injury following neurotrauma [14].

Association studies in human TBI may help to identify biomarkers of prognosis as well as targets to develop more focused treatment strategies. Previous studies have demonstrated the association between cerebrospinal fluid or blood levels of different cytokines and human TBI, but their relatively small sample sizes of patients, selection bias, inadequate handling of missing data and the confounding bias leave doubts about the independent association between cytokines and patients' prognosis. In the present study, we prospectively investigated the independent association between serum levels of anti-inflammatory IL-10 and pro-inflammatory TNF- $\alpha$ cytokines and hospital mortality of patients with severe TBI using a multiple logistic regression analysis.

\section{Patients and Methods}

We prospectively included 93 consecutive adult patients (age 18-79 years) with severe TBI from the metropolitan area of Florianópolis city (Santa Catarina state, southern Brazil), admitted to the intensive care unit (ICU) of the Hospital Governador Celso Ramos between April 2006 and September 2008, who met the inclusion criterion. The inclusion criterion was a Glasgow Coma Scale score (GCS) $\leq 8$ at hospital admission. Because of the low number of cases, victims of gunshot injuries and patients who died from brain death within $24 \mathrm{~h}$ after admission were excluded. For comparison, we randomly selected patients with mild TBI $(\mathrm{GCS}=13-15, \mathrm{n}=16)$ and moderate TBI (GCS $=9-12, \mathrm{n}=18)$, who came to our emergency room during the same time period and agreed to participate in the study. Informed consent was obtained from patients (mild cases) or their families (moderate and severe cases). The research protocol was approved by the Universidade Federal de Santa Catarina's Ethics Committee for Human Research (protocol 163/2005).

The demographic and hospital variables analyzed were: age, gender, computed tomography (CT) findings according to the Marshall CT classification [16] and presence of subarachnoid hemorrhage, presence of associated trauma (thorax, abdomen or limbs), GCS and pupil examination at admission. A blinded CT analysis was done during hospitalization by one of the researchers (M.M.B.) and confirmed by another (M.N.L.) when necessary. Most of these variables, isolated or combined, were proven to be associated with TBI outcome in our patients and other populations [1, 2, 16-20]. The analyzed outcome was death during hospitalization. The secondary end point was the incidence of nosocomial infections (pneumonia and urinary tract) and time to mechanical ventilation.

Blood samples were collected from all included patients on the first day after hospital admission (in the emergency room or ICU). Two additional samples were collected from patients with severe TBI according to the research team's schedule between the second and fourth day after ICU admission. Blood samples of patients admitted on weekends were collected on Monday mornings. The time span between TBI and blood sampling was determined by one of our investigators using the information collected from the rescue registration forms that were highly accurate. A volume of $5 \mathrm{ml}$ peripheral venous blood was collected and centrifuged. The serum was stored for $24 \mathrm{~h}$ at $-20^{\circ} \mathrm{C}$ and then at $-70^{\circ} \mathrm{C}$ until cytokine analysis.

To investigate the association between serum cytokine levels and TBI severity after an injury, we performed an initial screening of the single blood sample collected from patients with mild and moderate TBI and of the first sample collected from patients with severe TBI ( $\mathrm{n}=11$ patients/group). The serum sample was chosen in a randomized manner blinded to all hospitalization variables except the severity of trauma determined by the GCS. The cytokine analysis was blinded to the hospitalization variables and outcome of patients. For this initial serum cytokine screening, flow cytometry was employed using the $\mathrm{BD}^{\mathrm{TM}}$ Cytometric Bead Array (CBA) Human Th1/Th2 Cytokine kit (BD Biosciences, San Diego, Calif., USA). The CBA kits detect the following cytokines: IL-2 and IL-4 (detection limit $2.6 \mathrm{pg} / \mathrm{ml}$ ), IL-5 (detection limit $2.4 \mathrm{pg} /$ $\mathrm{ml}$ ), IL-10 and TNF- $\alpha$ (detection limit $2.8 \mathrm{pg} / \mathrm{ml}$ ), and IFN- $\gamma$ (detection limit $7.1 \mathrm{pg} / \mathrm{ml}$ ). Briefly, serum samples were incubated with the 6 cytokine capture beads and PE-conjugated detection antibodies for $3 \mathrm{~h}$ at room temperature. Samples were then washed and data acquired using either a FACSCalibur or a FACS Cantoll (BD Biosciences). Sample results were generated in graphical and tabular format using the GraphPad Prism 5.01.

Following cytokine measurements using CBA, confirmatory enzyme-linked immunosorbent assay (ELISA) commercial kits (e-Biosciences) were employed in serum samples from a larger number of cases with severe $(\mathrm{n}=93)$, moderate $(\mathrm{n}=18)$ and mild $(\mathrm{n}=16)$ TBI. 
Statistical Analysis

The normality of the continuous variables was determined by the one-sample Kolmogorov-Smirnov test. The correlation between serum cytokines and the severity of trauma (GCS) was analyzed by Spearman's test (for non-parametric data) or Pearson's test (for parametric data). Because of the asymmetric sample size of the groups, we used a non-parametric analysis (Kruskal-Wallis followed by Mann-Whitney test) to study the differences in the cytokine levels among patients with mild, moderate and severe (survivors and non-survivors) TBI. Differences among the serum cytokine levels of the three blood samples collected from patients with severe TBI were analyzed by Wilcoxon signed ranks test. The Kaplan-Meier curve was used to establish the cumulative probability of survival according to the IL-10 serum levels. Differences of cumulative survival between the categorical IL-10 groups were determined by the log-rank test.

The association between hospital mortality and continuous variables was analyzed by the Mann-Whitney test because of the relative asymmetry in the sample size of survivors and non-survivors. Continuous variables were also categorized. A univariate analysis using Cox's proportional hazards model was applied to identify demographic, clinical, radiological and neurosurgical variables and cytokine levels independently associated with hospital mortality. Variables showing a level of association with a $\mathrm{p}$ value $\leq 0.15$ were included in the multivariate analysis using Cox's proportional hazards model.

As there was a biological plausibility to our study design and in order to avoid a type II error, we did not employ any adjustments for the multiple tests using a more stringent cut-off level for " $p$ " level to minimize the possible bias affecting the cytokine levels due to multiple organ injuries, the variable 'associated trauma' was also included in the multivariate analysis. We also performed a separate analysis of association between serum IL-10 levels and hospital mortality of patients with isolated severe TBI only. All missing cases occurred by chance and are clearly described in the results tables.

The association between serum IL-10 levels and the occurrence of pneumonia or urinary tract infection was analyzed by Cox's proportional hazards model. The association between time under mechanical ventilation and serum IL-10 levels was analyzed using Spearman's test. Statistical analysis was done using the SPSS program 17.0 (Chicago, Ill., USA).

\section{Results}

Blood samples were collected within a median period (interquartile range (IQ) 25-75) of $10 \mathrm{~h}$ (IQ 5-18), $30 \mathrm{~h}$ (IQ 22-37) and $68 \mathrm{~h}$ (IQ 55-78) following TBI. To evaluate the elicited pro- and anti-inflammatory associated cytokine levels early on during TBI, we utilized CBA as a screening method in randomized patients' serum samples. Serum IL-2, IL-4, IL-5 and IFN- $\gamma$ levels were found to be undetectable in all evaluated groups (data not shown). These cytokines were also undetectable in samples collected at the first (median $12 \mathrm{~h}$, IQ 8-20), second (median $34 \mathrm{~h}$, IQ 23-37), and third (median $65 \mathrm{~h}$, IQ 56-79) time point after

IL-10 Is an Independent Biomarker of Severe TBI Prognosis severe TBI ( $\mathrm{n}=9$ patients/time point; data not shown). In contrast, increased levels of TNF- $\alpha$ and IL-10 were detected in the serum of TBI patients by CBA or ELISA. In addition, there were no statistically significant differences in the periods between TBI and blood sample collection from the three studied groups: severe $(n=93)$, moderate $(\mathrm{n}=18)$ and mild $(\mathrm{n}=16)$ TBI (Kruskal-Wallis, $\mathrm{p}=0.23$; data not shown). Despite the early augmentation of serum TNF- $\alpha$ levels after TBI, no significant correlation was observed between this parameter and the severity of the trauma (determined by GCS) and hospital mortality (fig. 1). However, serum IL-10 measurements displayed a statistically significant correlation with TBI severity determined by GCS (fig. 2a). These results are in accordance with previous findings [21], indicating that IL-10 is rapidly produced following TBI. These evidences indicate that TBI severity correlates with this anti-inflammatory cytokine during TBI. Such a hypothesis is supported since in the subset of patients with severe TBI (GCS $\leq 8)$, nonsurvivors were found to display higher amounts of serum IL-10 than survivors (fig. 2b).

Additionally, we performed an association analysis between IL-10 levels (serum collected at the first $(n=74)$ or second $(n=60)$ time point after trauma) and hospital mortality of patients with isolated severe TBI. Patients with severe TBI who died showed a significantly higher serum IL-10 level than survivors. At the first time point, the median serum IL-10 level (IQ 25-75) from non-survivors was found to be $120 \mathrm{pg} / \mathrm{ml}$ (IQ 60-260), which is significantly higher than that from survivors $(70 \mathrm{pg} / \mathrm{ml}$, IQ $40-110 ; p=0.01)$. A similar result was observed in samples collected at the second time point, which displayed IL-10 levels of $60 \mathrm{pg} / \mathrm{ml}$ (IQ 40-80) for survivors and $90 \mathrm{pg} / \mathrm{ml}$ (IQ 50-140) for non-survivors $(\mathrm{p}=0.02)$. There were no statistically significant differences $(\mathrm{p}=$ 1.0) between IL-10 levels measured in samples collected at the third time point after trauma (data not shown). In addition, serum TNF- $\alpha$ levels in samples from the three time points were also similar in survivors and non-survivors with isolated severe TBI $(\mathrm{p}>0.29)$. These results demonstrate that serum IL-10 levels may predict hospital mortality in patients with isolated TBI or in TBI associated with lesions in other organs.

All patients with mild TBI survived and only 1 patient with moderate TBI died. The Kaplan-Meier survival curves comparing the cumulative percentages of patients who survived according to their serum IL-10 levels (in pictograms per milliliters) measured $10 \mathrm{~h}$ after severe TBI are presented in figure 3. Patients with serum IL-10 levels $<50 \mathrm{pg} / \mathrm{ml}$ showed a significantly higher chance to sur- 


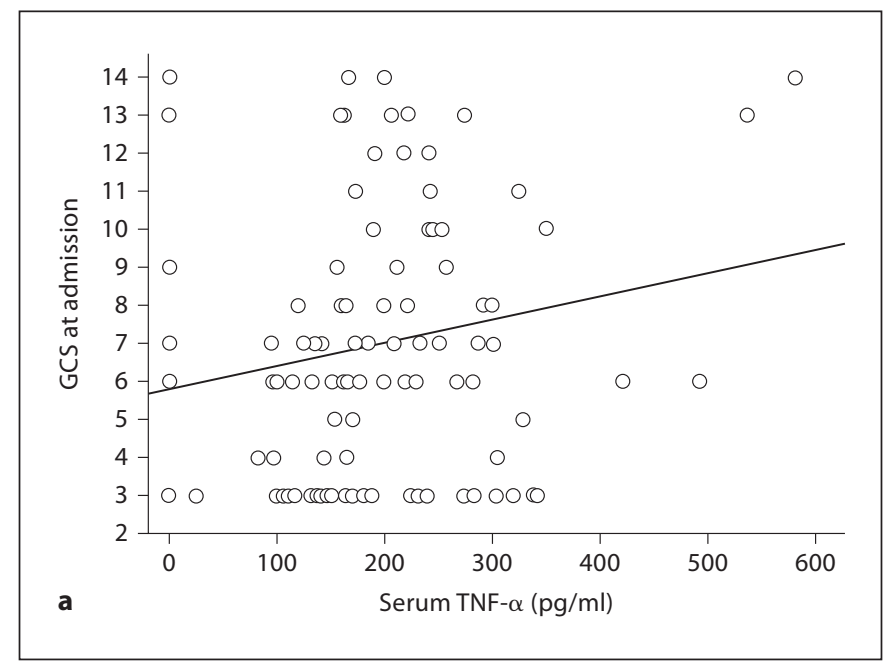

Fig. 1. a Correlation between the GCS at admission and serum TNF- $\alpha$, determined by ELISA, measured in the blood sample collected after a median period of $10 \mathrm{~h}$ (IQ 25-75 = 5-18) after TBI. There is a trend for a positive correlation between the GCS at admission and serum TNF- $\alpha$ (Pearson's correlation coefficient $=0.16, \mathrm{p}=0.08)$. $\mathbf{b}$ Serum TNF- $\alpha$, determined by ELISA,

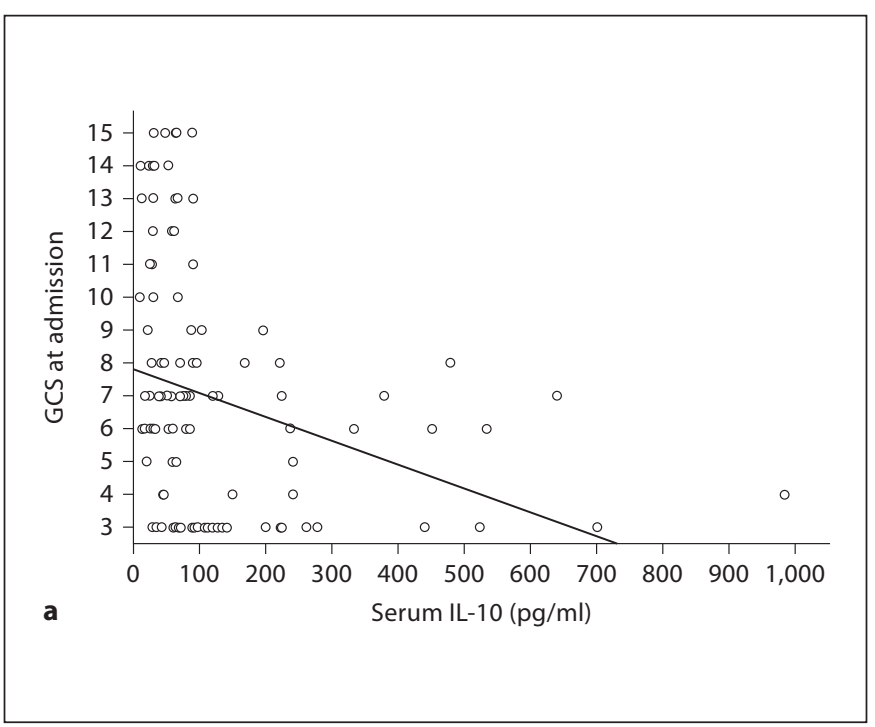

Fig. 2. a Correlation between the GCS at admission and serum IL-10, determined by ELISA, measured in the blood sample collected after a median period of $10 \mathrm{~h}$ (IQ 25-75 = 5-18) after TBI. There is a significant negative correlation $(\mathrm{p}<0.0001)$ between the GCS at admission and serum IL-10 (Spearman's correlation coefficient $=-0.42$ ). $\mathbf{b}$ Serum IL-10, determined by ELISA, measured in patients with severe (survivors and non-survivors), moderate and mild TBI. The non-survivors with severe TBI $(\mathrm{n}=35)$ showed a significant enhancement in serum IL-10 in comparison

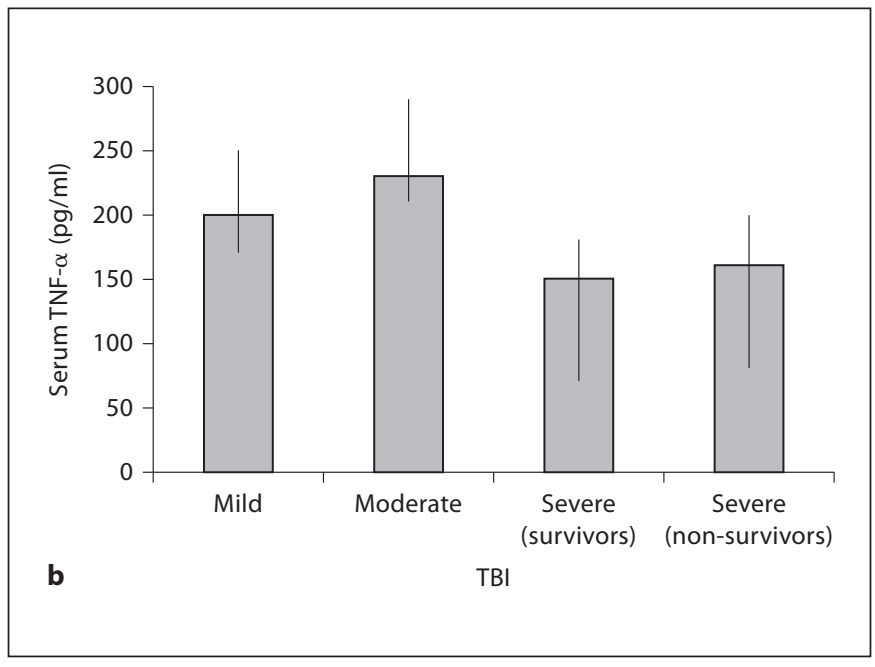

measured after $11 \mathrm{~h}$ (IQ $25-75=4-13$ ) in patients with severe (survivors and non-survivors), moderate and mild TBI. There was no statistically significant difference in the serum TNF- $\alpha$ levels among patients with severe (survivors and non-survivors), moderate and mild TBI $(\mathrm{p}=0.23)$. Data are expressed as medians and IQ ranges.

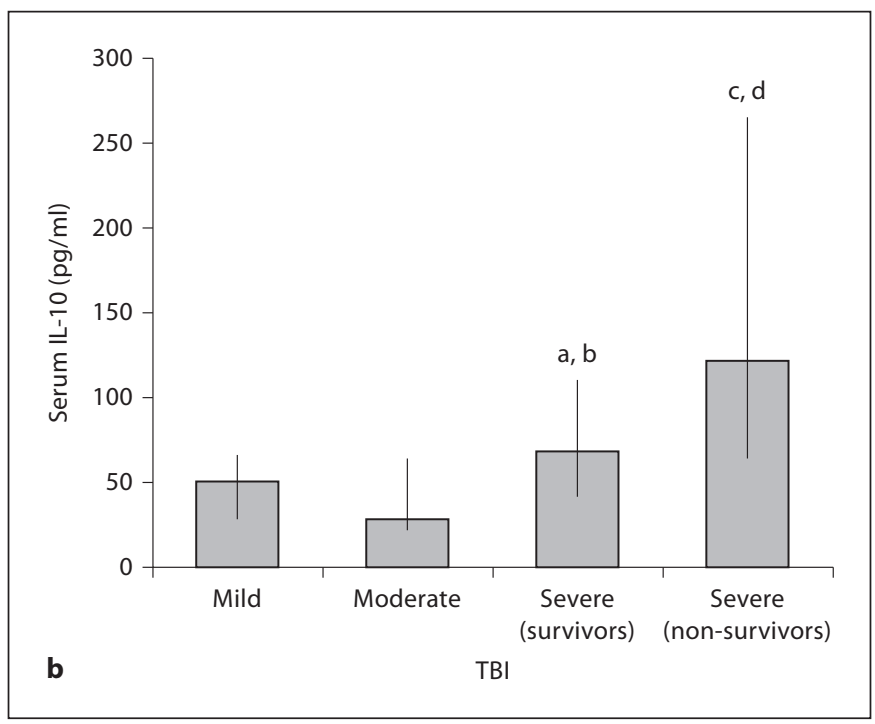

to survivors $(\mathrm{n}=58)$ and patients with moderate $(\mathrm{n}=18)$ or mild $(\mathrm{n}=16)$ TBI. ${ }^{\text {a }}$ Significant difference $(\mathrm{p}<0.001)$ between survivors with severe TBI and patients with mild TBI. ${ }^{\mathrm{b}}$ Significant difference $(p<0.001)$ between survivors with severe TBI and patients with moderate TBI. ${ }^{c}$ Significant difference $(p<0.02)$ between non-survivors with severe TBI and patients with moderate TBI. d Significant difference $(\mathrm{p}<0.01)$ between survivors and nonsurvivors with severe TBI. Data are expressed in medians and IQ ranges. 
vive than patients with higher levels $(\mathrm{p}<0.01)$. There were no differences in the survival rates of patients with serum IL-10 levels between 50 and $90 \mathrm{pg} / \mathrm{ml}$ and those with levels $>90 \mathrm{pg} / \mathrm{ml}(\mathrm{p}=0.73)$. Similar results were observed with IL-10 levels determined from the second blood sample (data not shown).

The clinical, demographic, radiological and neurosurgical variables, serum IL-10 levels and hospital mortality of patients with severe TBI are shown in table 1 . The mean age of our patients was 35 years and $82 \%$ were male. Thirty-five patients died during hospitalization, and TBI itself was the cause of death in 32 patients. One patient died due to heart infarction, one due to pneumonia, pleural effusion and cardiac arrest and one due to pneumonia evolving to sepsis, renal failure and cardiac arrest. These 3 patients died after the third blood sample collection. Hospital mortality was not associated with gender, CT findings at admission, associated trauma or the respiratory and hemodynamic parameters at ICU admission $(p \geq 0.30)$. There was a non-significant trend for a higher mortality of patients older than 44 years (hazard ration (HR) 1.6, 95\% confidence interval (CI) $0.8-3.2, \mathrm{p}=0.15$ ).

A GCS $<5$ at hospital admission was almost 3 times more frequently associated with hospital mortality than higher GCS (crude HR 2.9, 95\% CI 1.2-7.1, p = 0.02). Pupil abnormalities at hospital admission were approximately 4 times more frequently present in non-survivors than in survivors (crude HR 3.7, 95\% CI 3.7-8.2, p = 0.001). Importantly, the univariate analysis showed an association between higher IL-10 levels and hospital mortality. A serum IL-10 level $>90 \mathrm{pg} / \mathrm{ml}$ in the first blood sample was 6 times more frequently associated with death than an IL-10 level $<50 \mathrm{pg} / \mathrm{ml}$ (crude HR 6.5, 95\% CI 1.5-27.7, $\mathrm{p}=0.01$ ). Serum IL-10 levels between 50 and $90 \mathrm{pg} / \mathrm{ml}$ in the first sample were also 6 times more frequently associated with death (crude HR 5.7, 95\% CI 1.3-25.4, p = 0.02). Concerning serum IL-10 level determination in the second blood sample, there was a non-significant trend for an association between cytokine levels $>90 \mathrm{pg} / \mathrm{ml}$ and hospital mortality (crude HR 1.9, 95\% CI 0.8-4.7, p = 0.18) in comparison to lower levels. Serum IL-10 levels measured in the third blood sample were not associated with hospital mortality ( $\mathrm{p} \geq 0.30$ ). All these results remained unaltered when deaths not attributed to brain death were excluded (data not shown). The time span between TBI and the 3 blood sample collections does not differ between survivors and non-survivors ( $\mathrm{p}>0.22$; table 1$)$.

The multiple Cox proportional hazards model analysis is shown in table 2 . The presence of higher serum IL-10 levels $(>90 \mathrm{pg} / \mathrm{ml})$ in the first and second blood sample

IL-10 Is an Independent Biomarker of Severe TBI Prognosis

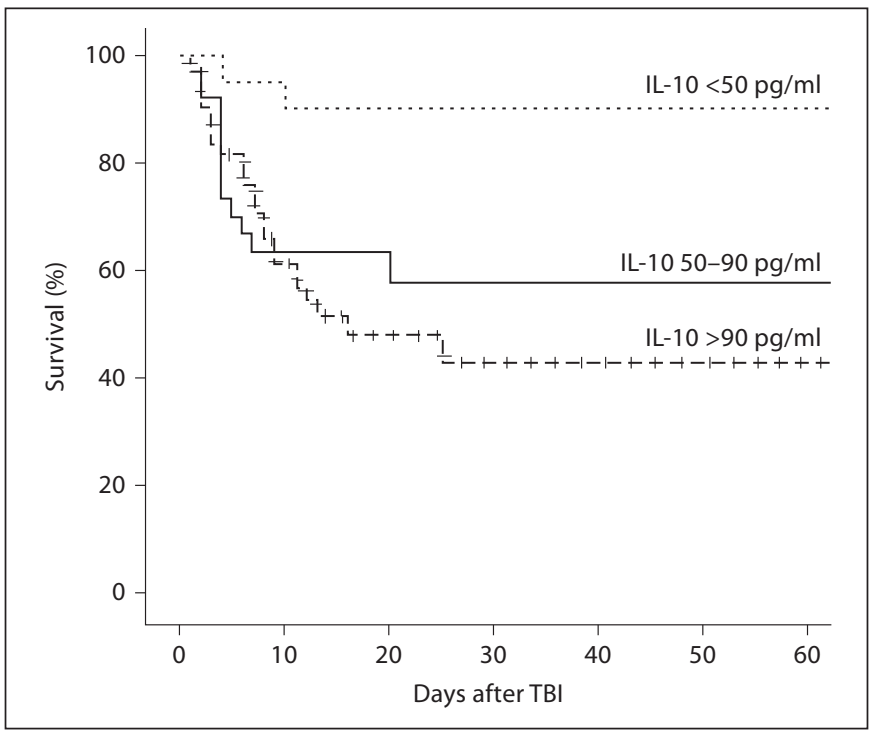

Fig. 3. Kaplan-Meier survival curves comparing the cumulative percentages of patients who survived according to their serum IL10 levels measured $10 \mathrm{~h}$ after severe TBI. Patients with serum IL10 levels $<50 \mathrm{pg} / \mathrm{ml}$ showed a significantly higher chance to survive than patients with higher levels (log-rank test, $\mathrm{p}<0.01$ ). There were no differences in the survival rates of patients with serum IL-10 levels between 50 and $90 \mathrm{pg} / \mathrm{ml}$ and those with levels $>90 \mathrm{pg} / \mathrm{ml}(\log$-rank test, $\mathrm{p}=0.73)$.

collected after severe TBI was significantly more frequently associated with hospital mortality than lower levels $(<50 \mathrm{pg} / \mathrm{ml})$ : adjusted HR 4.1, 95\% CI 1.1-18.9 (p = 0.04 ) versus adjusted odds ratio (OR) 5.4, 95\% CI 1.2-25.1 $(\mathrm{p}=0.03)$, respectively. These results were independently of age, GCS and pupils at admission or the presence of associated trauma (table 2). A serum IL-10 level between 50 and $90 \mathrm{pg} / \mathrm{ml}$ measured in the first blood sample shows a non-significant trend of independent association with death in comparison to lower levels (adjusted OR 4.8, 95\% CI $0.8-27.7, \mathrm{p}=0.08)$. We included the variable 'associated trauma' in the final model of the multiple Cox proportional hazards model analysis to control for a possible confounding bias related to IL-10 changes due to the presence of other organ lesions.

The multiple Cox proportional hazards models are presented in table 2. After adjusting for pupil abnormalities at admission, GCS, age and associated trauma, a serum IL-10 level between 50 and $90 \mathrm{pg} / \mathrm{ml}$ at $10 \mathrm{~h}$ after severe TBI was 4 times more frequently associated with hospital mortality than lower levels (adjusted HR 4.0, 95\% CI $0.9-18.5, \mathrm{p}=0.07)$. The same independent $\mathrm{HR}$ for death was observed for serum IL-10 levels $>90 \mathrm{pg} / \mathrm{ml}$ in comparison with lower levels (adjusted HR 4.1, 95\% CI 
Table 1. Clinical, demographic, radiological and neurosurgical variables and serum IL-10 levels according to hospital mortality

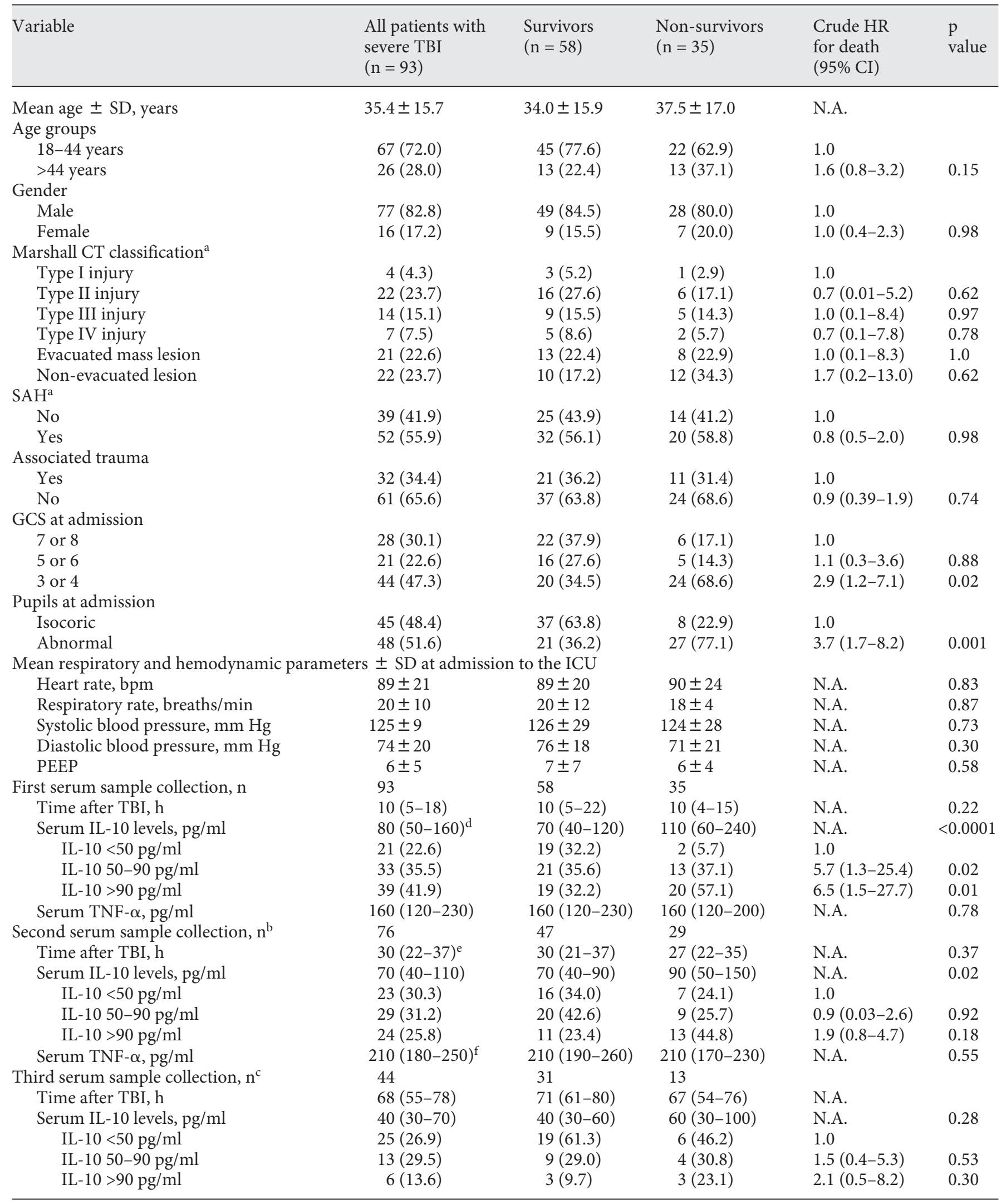

(For table footnote see next page.) 
$1.1-18.9, \mathrm{p}=0.04)$. A serum IL-10 level $>90 \mathrm{pg} / \mathrm{ml}$ determined $30 \mathrm{~h}$ after severe TBI was 2 times more frequently associated with death than lower levels (adjusted HR 2.5, 95\% CI 1.09-6.39, $\mathrm{p}=0.03$ ).

The IL-10 levels from the third blood sample were not included in the multiple Cox proportional hazards model because they were not associated with prognosis in the univariate analysis and there was a large number of samples missing. Altogether, these data indicate that IL-10 produced early on in the serum is an independent factor predicting TBI outcome.

Thirty-eight (41\%) patients developed pneumonia and $9(10 \%)$ urinary tract infection. The serum IL-10 levels determined 10 or $30 \mathrm{~h}$ after severe TBI were not associated with the occurrence of pneumonia or urinary tract infection ( $\mathrm{p}>0.26$ by log-rank test) and did not correlate with the time to mechanical ventilation $\left(\mathrm{R}^{2}\right.$ correlation $<-0.15, \mathrm{p}>0.27)$.

\section{Discussion}

The present study demonstrates that elevated serum IL-10 levels, but not TNF- $\alpha$ levels, after TBI are independently associated with hospital mortality in patients with severe TBI. As previously demonstrated by others, the initial production of IL-10 in serum increases within the first 3 days after an injury $[19,20,22]$. Despite statistically significant correlations between IL-10 and GCS, the clinical relevance of this association may be not relevant $\left(\mathrm{r}^{2}=\right.$ -0.42 ) and may be influenced by some extreme values.

The association between higher serum IL-10 levels and mortality due to TBI was previously demonstrated by Bell et al. [20] in children and adults with body injury including some patients without TBI [23], but these findings were not further confirmed by Dziurdzik et al. [19] in adult patients with TBI. The small sample sizes of patients of these previous studies may help to explain, at least in part, their contradictory findings. The observed enhanced serum IL10 levels may be due to an additional extracranial injury [24], or a rapid secretion of monocyte populations after a sympathetic activation in isolated TBI [25] or it may even be produced in high concentrations by resident microglia and infiltrating monocytes/macrophages in the acute phase of injury [12]. The latter mechanism may also contribute to the elevation of serum TNF- $\alpha$ levels [12]. Corroborating previous literature [12], we observed that TNF$\alpha$ was detected in serum after the first 2 days after severe TBI. However, this cytokine was found to be not associated with TBI severity measured by GCS and neither with hospital mortality in patients with severe TBI.

The present data support that the association between elevated serum IL-10 measured after severe TBI and hospital mortality in the cohort reported here is not spurious because: (1) the hypothesis was tested using an adequate sample size of patients; (2) the possible imbalanced distribution of variables between survivors and non-survivors, shown to be independently associated with the prognosis of severe TBI, has been controlled for by the regression analysis, and (3) the observed unaltered levels of IL-2, IL-4, IL-5 and IFN- $\gamma$ measured in 30 patient samples reduce the possibility of changes in cytokine levels due to an unspecific reaction to injury.

IL-10 enhances the pentraxin 3 (PTX3), a humoral component of the innate immune system, production by dentritic cells of myelomonocytic origin [26], and recently we have demonstrated that serum PTX3 levels are also independently associated with hospital mortality in patients with severe TBI [9]. Taken together, these findings may suggest an interaction or independent participation of IL-10 and PTX3 in TBI-induced immunological changes. Nevertheless, the present study design, which was similar to that applied in the PTX3 study [9], does not allow us to further address whether the observed serum IL-10 and PTX3 enhancement in non-survivors is protective or deleterious.

(Footnote from table 1.)

Values are numbers (with percentages in parentheses) or means (with IQ 25-75 in parentheses), as appropriate and unless otherwise noted.

$\mathrm{HR}=$ Hazard ratio determined by Cox's proportional hazards model; N.A. = not applicable; $\mathrm{SAH}=$ subarachnoid haemorrhage; $\mathrm{PEEP}=$ positive end-expiratory pressure.

${ }^{\text {a }} \mathrm{CT}$ was not analyzed in 2 cases. ${ }^{\mathrm{b}}$ Serum IL-10 was not examined in 17 patients in the second blood sample; 7 patients had died before the sampling time, and in 10 the second sample was not collected by the research team. ${ }^{c}$ Serum IL-10 was not examined in 49 patients on the third day; 10 had died before the sampling time, and in 39 the third sample was not collected by the research team. ${ }^{\mathrm{d}}$ The serum IL-10 levels decreased significantly in the second and third sample compared with the first sample ( $\mathrm{p} \leq 0.005)$. e The serum IL-10 levels in the third sample was significantly lower than in the second blood sample $(\mathrm{p}<0.05) .{ }^{\mathrm{f}}$ There was a significant enhancement in the TNF- $\alpha$ level of the second sample in comparison to the first blood sample. TNF- $\alpha$ was not measured in the third blood sample. 
Table 2. Independent association between serum IL-10 levels measured on the first and second day after severe TBI and hospital mortality

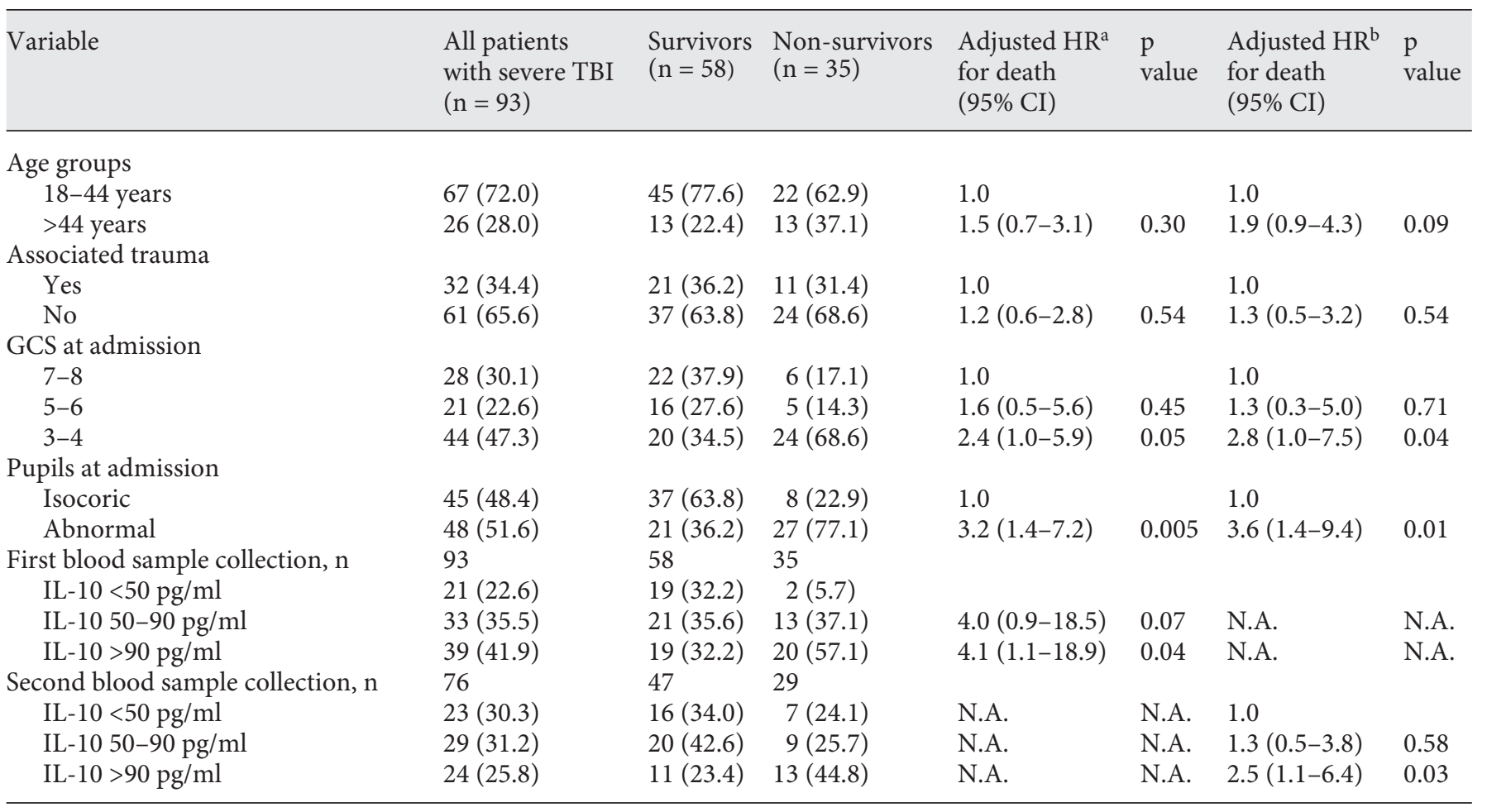

All values are numbers (with percentages in parentheses).

N.A. = Not applicable.

${ }^{a}$ HR adjusted for age, associated trauma, GCS at admission, pupils at admission and serum IL-10 measured in the first collected blood sample. ${ }^{b}$ HR adjusted for age, associated trauma,
GCS at admission, pupils at admission and serum IL-10 measured in the second collected blood sample. Serum IL-10 was not examined in 17 patients on the second day; 7 patients had died before the sampling time, and in 10 the second blood sample was not collected.
Importantly, emerging evidence implicates the nature of IL-10 to possible neuroprotective effects elicited by inflammatory settings. IL-10 reduces pro-inflammatory responses after ischemic stroke primarily by acting on the glia and endothelium, but it also protects cortical neurons by activating PI-3 kinase and STAT-3 pathways [27]. We speculate that the observed IL-10 enhancement contributes directly and indirectly to neuroprotection after TBI. Interestingly, Knoblach and Faden [28] showed that systemic (intravenous or subcutaneous) but not intracerebroventricular administration of IL-10 improved neurological outcomes in a lateral fluid-percussion model of TBI, suggesting that IL-10-associated pathways could also serve as a therapeutic target for TBI treatment. This question merits further investigation.

If confirmed in other populations, our findings could indicate that IL-10 may be a useful clinical biomarker of TBI severity. The association between serum IL-10 levels and both early and long-term outcomes evaluated by fine motor skills, cognitive and psychiatric evaluation as well as quality of life aspects is an important point to be further investigated in patients with TBI.

\section{Acknowledgments}

This work was supported by grants from the Conselho Nacional de Desenvolvimento Científico e Tecnológico (CNPq), the Coordenação de Aperfeiçoamento de Pessoal de Nível Superior, the Programa de Apoio aos Núcleos de Excelência and the Fundação de Apoio a Pesquisa do Estado de Santa Catarina (all from Brazil). R.D.S.P., A.B. and R.W. are supported by research fellowships from $\mathrm{CNPq}$ - Brazil. The authors received technical support for the biological sample collection from the Laboratório Biomédico (Florianópolis) under the supervision of Pharm. Saulo Correia de Mello. The authors thank all medical and nursing staff of the Serviço de Terapia Intensiva (Hospital Governador Celso Ramos) for their kind cooperation during the study. 


\section{References}

$>1$ Martins ET, Linhares MN, Sousa DS, et al: Mortality in severe traumatic brain injury: a multivariated analysis of 748 patients from Florianópolis city. J Trauma 2009;67:85-90.

-2 MRC CRASH Trial Collaborators, Perel P, Arango M, Clayton T, Edwards P, Komolafe E, Poccock S, Roberts I, Shakur H, Steyerberg E, Yutthakasemsunt S: Predicting outcome after traumatic brain injury: practical prognostic models based on large cohort of international patients. BMJ 2008;336:425429.

$>3$ Diaz AP, Schwarzbold ML, Thais ME, Hohl A, Bertotti MM, Schmoeller R, Nunes JC, Prediger R, Linhares MN, Guarnieri R, Walz R: Psychiatric disorders and health-related quality of life after severe traumatic brain injury: a prospective study. J Neurotrauma 2012;29:1029-1037.

4 Thais ME, Cavallazzi G, Schwarzbold ML, Diaz AP, Ritter C, Petronilho F, Hohl A, Prediger RD, Linhares MN, Pizzol FD, Walz R: Plasma levels of oxidative stress biomarkers and long-term cognitive performance after severe head injury. CNS Neurosci Therap 2012;18:606-608.

5 Schwarzbold M, Diaz A, Martins ET, Rufino A, Amante LN, Thais ME, Quevedo J, Hohl A, Linhares MN, Walz R: Psychiatric disorders and traumatic brain injury. Neuropsychiatr Dis Treat 2008;4:797-816.

6 Lu J, Goh SJ, Tng PY, et al: Systemic inflammatory response following acute traumatic brain injury. Front Biosci 2009; 14:37953813.

$>7$ Kadhim HJ, Duchateau J, Sebire G: Cytokines and brain injury: invited review. J Intensive Care Med 2008;23:236-249.

$>8$ Soriano SG, Piva S: Central nervous system inflammation. Eur J Anaesthesiol Suppl 2008;42:154-159.

$>9$ Gullo JS, Bertotti MM, Silva CC, Schwarzbold M, Diaz AP, Soares FM, Freitas FC, Nunes J, Pinheiro JT, Morato EF, Prediger RD, Linhares MN, Walz R: Hospital mortality of patients with severe traumatic brain injury is associated with serum PTX3 levels. Neurocrit Care 2011;14:194-199.
10 Schwarzbold ML, Rial D, De Bem T, Machado DG, Cunha MP, dos Santos AA, dos Santos DB, Figueiredo CP, Farina M, Goldfeder EM, Rodrigues AL, Prediger RD, Walz R: Effects of traumatic brain injury of different severities on emotional, cognitive, and oxidative stress-related parameters in mice. J Neurotrauma 2010;27:1883-1893.

11 Engelhardt B: Immune cell entry into the central nervous system: involvement of adhesion molecules and chemokines. J Neurol Sci 2008;274:23-26.

12 D’Mello C, Le T, Swain MG: Cerebral microglia recruit monocytes into the brain in response to tumor necrosis factor alpha signaling during peripheral organ inflammation. J Neurosci 2009;29:2089-2102.

13 Kirchhoff C, Buhmann S, Bogner V, et al: Cerebrospinal IL10 concentration is elevated in non-survivors as compared to survivors after severe traumatic brain injury. Eur J Med Res 2008;13:464-468.

14 Laird MD, Vender JR, Dhandapani KM: Opposing roles for reactive astrocytes following traumatic brain injury. Neurosignals 2008; 16:154-164.

15 Maas AI, Steyerberg EW, Butcher I, et al: Prognostic value of computerized tomography scan characteristics in traumatic brain injury: results from the IMPACT study. J Neurotrauma 2007;24:303-314.

16 McHugh GS, Engel DC, Butcher I, et al: Prognostic value of secondary insults in traumatic brain injury: results from the IMPACT study. J Neurotrauma 2007;24: 287-293.

17 Murray GD, Butcher I, McHugh GS, et al: Multivariable prognostic analysis in traumatic brain injury: results from the IMPACT study. J Neurotrauma 2007;24:329-337.

18 Van Beek JG, Mushkudiani NA, Steyerberg EW, et al: Prognostic value of admission laboratory parameters in traumatic brain injury: results from the IMPACT study. J Neurotrauma 2007;24:315-328.

19 Dziurdzik P, Krawczyk L, Jalowiecki P, Kondera-Anasz Z, Menon L: Serum interleukin-10 in ICU patients with severe acute central nervous system injuries. Inflamm Res 2004;53:338-343.
20 Bell MJ, Kochanek PM, Doughty LA, et al: Interleukin- 6 and interleukin-10 in cerebrospinal fluid after severe traumatic brain injury in children. J Neurotrauma 1997;14: 451-457.

21 Marmarou A, Lu J, Butcher I, et al: Prognostic value of the Glasgow Coma Scale and pupil reactivity in traumatic brain injury assessed pre-hospital and on enrollment: an IMPACT analysis. J Neurotrauma 2007;24: 270-280.

-22 Csuka E, Morganti-Kossmann MC, Lenzlinger PM, Joller H, Trentz O, Kossmann T: IL-10 levels in cerebrospinal fluid and serum of patients with severe traumatic brain injury: relationship to IL-6, TNF-alpha, TGF beta1 and blood-brain barrier function. J Neuroimmunol 1999;101:211-221.

23 Neidhardt R, Keel M, Steckholzer U, et al: Relationship of interleukin-10 plasma levels to severity of injury and clinical outcome in injured patients. J Trauma 1997;42:863870.71 .

24 Shiozaki T, Hayakata T, Tasaki O, et al: Cerebrospinal fluid concentrations of anti-inflammatory mediators in early-phase severe traumatic brain injury. Shock 2005;23:406410.

25 Woiciechowsky C, Asadullah K, Nestler D, et al: Sympathetic activation triggers systemic interleukin-10 release in immunodepression induced by brain injury. Nat Med 1998;4: 808-813.

26 Doni A, Michela M, Bottazzi B, Peri G, Valentino S, Polentarutti N, Garlanda C, Mantovani A: Regulation of PTX3, a key component of humoral innate immunity in human dendritic cells: stimulation by IL-10 and inhibition by IFN-gamma. J Leukoc Biol 2006; 79:797-802.

27 Sharma S, Yang B, Xi X, Grotta JC, Aronowski J, Savitz SI: IL-10 directly protects cortical neurons by activating PI-3 kinase and STAT-3 pathways. Brain Res 2011;1373:189194.

28 Knoblach SM, Faden AI: Interleukin-10 improves outcome and alters proinflammatory cytokine expression after experimental traumatic brain injury. Exp Neurol 1998;153: 143-151. 